\title{
КОМПЛЕКСНЫЙ ПОДХОД В СОПРОВОЖДЕНИИ ДЕТЕЙ С ИЗБЫТОЧНЫМ ВЕСОМ И ОЖИРЕНИЕМ: ПОЗИЦИЯ СПЕЦИАЛИСТА ПО ПЕДИАТРИИ, ЭНДОКРИНОЛОГИИ И ДИЕТОЛОГИИ, ПРАКТИКУЮЩЕГО НА БАЗЕ ДЕТСКОГО ЦЕНТРА ЗДОРОВЬЯ
}

\author{
О.В. Цимбалова', Т.Е. Таранушенко ${ }^{2}$, Н.Г. Киселева ${ }^{2}$ \\ 'Детский чентр здоровья КГБУЗ КГДП №»2, \\ ${ }^{2}$ ФГБОУ ВО КрасГМУ им. проф. В.Ф.Войно-Ясенецкого Минздрава России, г. Красноярск
}

\begin{abstract}
АКтУАЛЬНОСТЬ. Ожирение у детей - проблема современного общества и здравоохранения, которая достигла масштаба эпидемии. По данным ВОЗ, в 2016 г. в мире от ожирения и избыточного веса страдали 41 млн. детей в возрасте до 5 лет и 340 млн. детей и подростков в возрасте 5-19 лет. В России у детей в возрасте 5-17 лет избыточная масса тела зафиксирована у 21,9\% мальчиков и 19,3\% девочек, а ожирение - у 6,8\% мальчиков и 5,3\% девочек. Максимально высокая распространенность избыточной массы тела и ожирения зарегистрирована среди мальчиков 10-летнего возраста (Н.П. Соболева, 2014).

Согласно мнению экспертов ВОЗ, «в современном обществе дети и молодежь подвергаются множеству факторов, способных оказывать влияние на развитие ожирения».

Несбалансированное, избыточное по калорийности и дефицитное по содержанию микронутриентов питание является серьезной проблемой, требующей комплексного подхода.

ЦЕЛЬ ИССЛЕДОВАНИЯ: Провести комплексную оценку эффективности мероприятий, Включенных в программу по снижению веса и направленных на улучшение метаболизма, стимуляцию процессов энергетического обмена, поддержание биохимического и гормонального гомеостаза организма.
\end{abstract}

МАТЕРИАЛЫ И МЕТОДЫ ИССЛЕДОВАНИЯ. В аналИз вКЛючеНЫ 63 ребенка обоего пола от 5 до 17 лет, которые наблюдались в Детском центре здоровья по поводу избыточной массы тела (8 человек) и ожирения (55 человек). Обследование пациентов проводилось в соответствии с клиническими рекомендациями, по показаниям выполнялись дополнительные консультации и исследования.

С каждым из пациентов обсуждались вопросы диетотерапии и физической нагрузки. Дополнительно все дети рассматриваемой группы получали обязательную нутрицевтическую поддержку: витамин D, препараты йода, Омега-3 жирные кислоты (в течение всего периода наблюдения), микроэлементы (магний, селен, цинк) и пробиотические препараты (продолжительность курсов в соответствии с инструкцией к препарату) в возрастных дозировках.

Сведения динамического наблюдения: результаты клинического осмотра, индекс массы тела (ИМТ), данные биоимпедансометрии, показатели лабораторных и инструментальных обследований.

РЕЗУЛЬТАТЫ ИССЛЕДОВАНИЯ. У всех обследованных в начала наблюдения отмечены изменения в липидном спектре крови; наиболее частыми проявлениями дислипидемии были сниженные значения ЛПВП, повышенные уровни триглицеридов и индекса атерогенности. При оценке углеводного обмена нарушенная гликемия натощак $(\mathrm{H} Г \mathrm{H})$ и нарушенная толерантность к глюкозе (НТГ) установлена у 2 детей (по 1 случаю соответственно). Оценка гормонального профиля показала гиперинсулинемию с подтвержденной инсулинорезистентностью (индекс НОМА более 3,2 ) в 29 наблюдениях, что составило $46 \%$.

При оценке функции щитовидной железы снижение свободного Т4 в сочетании с увеличением ТТГ имели 2 человека (3,1\%), у которых впервые диагностирован первичный приобретенный гипотиреоз. Увеличение ТТГ при нормальном свободном Т4 отмечено у 8 обследованных (12,6\%), которые ранее не имели каких-либо указаний на тиреоидную патологию.

По данным УЗИ органов брюшной полости наиболее частыми (38 наблюдений - 60,3\%) были указания на диффузные изменения в поджелудочной железе и (или) печени в отсутствии функциональных расстройств; при этом наиболее вероятной причиной структурных нарушений печени следует считать жировой гепатоз. 


\section{СБОРНИК ТЕЗИСОВ}

XVII Российская научно-практическая конференция детских эндокринологов «Достижения науки в практику детского эндокринолога»

Биоимпедансометрия показала увеличение содержания жировой массы, снижение активной клеточной массы (АКМ) у детей с повышенным индексом массы тела (ИМТ).

Контрольное обследование по окончанию проведенного лечения у всех наблюдаемых пациентов не выявило случаев повышения ИМТ и ухудшение данных биоимпедансометрии. Снижение веса по результатам биоимпедансометрии произошло у всех детей за счет уменьшения жировой массы и жидкости на фоне увеличения показателя активной клеточной массы (АКМ), что может свидетельствовать об активации метаболизма и улучшении состояния энергетического обмена. Положительная динамика анализируемых показателей зарегистрирована у 58 человек, что составила 92\%. Отсутствие каких-либо изменений имели 5 детей (8\%), которые продолжают наблюдаться.

Динамика результатов биохимического анализа крови у всех детей показала улучшение показателей липидного профиля, снижение уровня инсулина, нормализация уровня ТТГ, сТ4.

ЗАКЛЮчЕНИЕ. Не маловажным условием эффективного снижения избыточного веса ребенка и поддержания в дальнейшем целевых значений ИМТ, данных биоимпедансометрии и биохимических показателей является комплексный подход, который успешно реализуется на базе Детских центров здоровья и включает, наряду с мотивацией и адекватной физической активностью, современные принципы диетологии, а также нутрицевтическую поддержку, направленную на улучшение метаболизма, стимуляцию процессов анаэробного и аэробного обмена, поддержание биохимического и гормонального гомеостаза детского организма. 